\title{
Climate change scenarios for the Nordic countries
}

\author{
Tómas Jóhannesson ${ }^{1, *}$, Trausti Jónsson ${ }^{2}$, Erland Källén ${ }^{3, * *}$, Eigil Kaas ${ }^{3}$ \\ 'Orkustofnum (National Energy Authority) Grensásvegi 9, IS-108 Reykjavík, Iceland \\ ${ }^{2}$ Veðurstofa Íslands (Icelandic Meteorological Office), Bústaðavegi 9, IS-150 Reykjavík, Iceland \\ ${ }^{3}$ Danish Meteorological Institute, Lyngbyvej 100, DK-2100 Copenhagen, Denmark
}

\begin{abstract}
A climate change scenario for the Nordic countries has been defined for application in hydrological models in the Nordic research project 'Climate Change and Energy Production' The scenario is based on a subjective evaluation of several recent results from global coupled atmosphere and ocean general circulation models (GCMs) and on a statistical downscaling of the model results. The scenario specifies a warming rate which ranges from $0.3^{\circ} \mathrm{C}$ per decade for Iceland and the Faeroe Islands to $0.45^{\circ} \mathrm{C}$ per decade for eastern Finland and the northernmost parts of Sweden. There are marked seasonal and regional differences in the warming rate. Summer warming is relatively uniform over the area, ranging from $0.25^{\circ} \mathrm{C}$ per decade in Iceland and the Faeroe Islands to $0.3^{\circ} \mathrm{C}$ per decade in Finland. Winter warming is more variable, ranging from $0.35^{\circ} \mathrm{C}$ per decade in the North Atlantic area to $0.6^{\circ} \mathrm{C}$ per decade in Finland. Precipitation is increased by 3 to $6 \%$ per degree of warming, yielding an increase ranging from $1 \%$ per decade during the summer season in Finland, Sweden and eastern Norway to $2.5 \%$ per decade during the winter season in western Norway. Climate in the Nordic countries is characterized by low-frequency natural variability on decadal time scales which is thought to be partly driven by changes in the thermohaline circulation of the North Atlantic. Future behaviour of the North Atlantic ocean circulation is highly uncertain, and model predictions of climate development in this nart of the world are perhaps more difficult than for most other regions. Other sources of uncertainty in GCM model computations apply to the North Atlantic region as well as to other regions of the world, e.g. coarse model resolution, somewhat arbitrary coupling of the ocean and the atmosphere and uncertain parameterizations of clouds and precipitation. In view of these difficulties, the scenario must be considered an extremely uncertain, although plausible, description of what might happen in the future rather than a prediction of what most likely will happen.
\end{abstract}

KEY WORDS: Climate scenarios - Nordic countries - Downscaling

\section{INTRODUCTION}

It is estimated that the global mean surface air temperature of the earth will rise at a rate on the order of $0.3^{\circ} \mathrm{C}$ per decade during the coming decades due to increasing concentrations of $\mathrm{CO}_{2}$ and other trace gases in the atmosphere (IPCC 1990, 1992). If it occurs, this warming will have pronounced effects on hydrological systems, which are of great economic importance for many sectors of modern industrialized societies. The Nordic research project 'Climate

- Present affiliation: Veðurstofa Íslands (Icelandic Meteorological Office), Bústadavegi 9, IS-150 Reykjavik, Iceland. E-mail: tj@vedur.is

*Present affiliation: Department of Meteorology, University of Stockholm, Arrhenius Laboratory, S-10691 Stockholm, Sweden
Change and Energy Production' (Sæelthun 1992) was started in 1991 by CHIN (Directors of the Hydrological Institutes in the Nordic countries) and KOHYNO (The Nordic Coordinating Committee for Hydrology) with the aim of assessing the hydrological effects of global warming in the Nordic countries with special emphasis on the possible consequences for the operation and planning of hydroelectric power plants. In this paper we describe the rationale behind the climate scenario which has been defined for use in this research project. We start with a summary of climate change scenarios which have been defined for the Nordic countries in the past. We then review recent literature on the results of GCM computations, with special emphasis on the North Atlantic area. The scenario described here is derived partly from downscaling of GCM model output and partly from a sub- 
jective evaluation of available direct GCM model output. Finally, we describe the statistical downscaling and our derivation of a scenario based on the downscaling and other available evidence.

\section{CLIMATE CHANGE SCENARIOS}

A climate change scenario is not a prediction of future climate. Rather, it is an internally consistent specification of possible climate development. Climate change scenarios are first and foremost research tools which are used to assess plausible consequences of future climate changes in the absence of reliable predictions of future climate. Climate change scenarios are of several different types, e.g. synthetic scenarios, analogue scenarios, scenarios from general circulation models (GCMs) and composite scenarios (cf. Carter et al. 1992, 1993).

Synthetic scenarios are defined by changing climatic elements by an arbitrary amount, often based on a qualitative interpretation of GCM model results. They are useful in many circumstances, but have the drawback that the adjustments may not be physically plausible or consistent. Therefore, synthetic scenarios are in general not recommended except for sensitivity analysis (Carter et al. 1992). These drawbacks may be partially eliminated by basing the adjustments on an evaluation of GCM results, meteorological observations or climatological analogues, in which case the resulting scenario will be more akin to a composite scenario as described below.

Analogue scenarios can be subdivided into historical instrumentally based scenarios, palaeoclimatic analogues and spatial analogues. They have the main advantage that they correspond to real climate conditions, past or present. Conditions which determine future climate are, however, likely to be fundamentally different from the conditions that shaped the analogue climate. Differences between the present climate and the analogue climate may, therefore, provide a misleading indication of the nature of future climate changes. In spite of these difficulties, climatological analogues provide important evidence for derivation of composite climate change scenarios.

Scenarios from GCMs are derived from the output of GCM model runs corresponding to increased concentrations of $\mathrm{CO}_{2}$ and other trace gases in the atmosphere. GCMs attempt to simulate the physical processes that determine global climate. They are, in spite of various difficulties, the only method which can be used for tracking the complex interactions between changes in the radiative forcing and the circulation of the atmosphere and ocean which will determine future climate development. Scenarios from GCMs can be based on direct model output or derived by more sophisticated techniques, as further described below.

Composite scenarios are derived by combining some of the above methods or output from more than one GCM. Sometimes the combination is based primarily on subjective evaluation of available evidence (observations, palaeoclimate, model output, etc.), but it can also be based on more quantitative techniques.

A number of climate scenarios have been defined for the Nordic countries. Early Finnish and Icelandic studies used scenarios based on GCM model output (using the GISS model for $2 \times \mathrm{CO}_{2}$ conditions) in addition to temporal and spatial analogue scenarios (Bergthórsson et al. 1987, Kettunen et al. 1987). Aittoniemi (1992) defined 3 scenarios for 2025 with temperature increases in the range 1.5 to $6.0^{\circ} \mathrm{C}$ (winter) and 0.8 to $3.0^{\circ} \mathrm{C}$ (summer) and precipitation increases between 10 and $35 \%$ in a study of climate change impact on energy production.

The Norwegian climate change assessment (Miljøverndepartementet 1991) was based on scenarios derived from $2 \times \mathrm{CO}_{2}$ GCM model runs which were assumed to apply around 2020 to 2050 . The 'most probable' scenario specified a temperature increase of 1.5 to $3.5^{\circ} \mathrm{C}$ and a precipitation increase of 5 to $15 \%$, depending on location (inland/coast) and season. Alexandersson \& Dahlström (1992) defined a climate change scenario for Sweden around 2030 which specifies a warming of 0.0 to $1.5^{\circ} \mathrm{C}$ and an increase in precipitation of 0 to $10 \%$, depending on location and season, compared to 1990 values. The Danish climate change assessment (Fenger \& Torp 1992) suggested temperature increases of $3.5 \pm 1.5^{\circ} \mathrm{C}$ (winter) and $2.0 \pm$ $1.0^{\circ} \mathrm{C}$ (summer) and a precipitation increase of 10 to $15 \%$ for Denmark in 2080. A report by Karlén et al. (1993) published by Elforsk (the Swedish electrical utilities' joint company for research and development) summarizes recent research on climate changes and human influence on climate and expresses serious reservations with regard to climate change scenarios based on GCM results.

The Finnish Research Programme of Climate Change (SILMU) proposed a simple preliminary 'best guess' climate change scenario for evaluating potential economic and social impacts of climate change (e.g. Carter 1992). This scenario specifies a warming rate of $0.4^{\circ} \mathrm{C}$ per decade and a precipitation increase of $3 \%$ per decade in winter, but no precipitation increase in summer. SILMU organized a workshop on techniques for developing climatic scenarios in Espoo, Finland, in June 1993 (Carter et al. 1993). Best estimates suggested by the experts at the workshop for the Nordic climate by the year 2100 were: (1) mean annual temperature will increase by $3^{\circ} \mathrm{C}$ with a range of 2 to $5^{\circ} \mathrm{C}$ and an east-west gradient, with somewhat less warm- 
ing in the North Atlantic than in Finland; and (2) winter precipitation may increase by a few percent, but summer changes may be positive or negative.

The climate change scenario described here is based primarily on recent results from coupled atmosphere and ocean GCMs. A statistical downscaling procedure for deriving future climate at selected Nordic meteorological stations from GCM model output was developed to aid in deriving the scenario, and the results were compared to direct model output (Kaas 1993a, b, 1994). The final scenario is based on a subjective evaluation of available output from coupled atmosphere and ocean GCMs and on the results of the statistical downscaling, with some input from historical observations and climatological analogues. The scenario is thus of the composite type as defined above.

A climate change scenario is defined with respect to a climatological baseline which determines a reference point for the projected climate changes. The climatological baseline for the project 'Climate Change and Energy Production' is the standard normal period 1961 to 1990. The scenario specifies changes in temperature and precipitation, as these are the most important input variables for hydrological modelling where the scenario will be applied. Hydrological simulations have been performed for time windows centered around 2020, 2050 and 2090 (i.e. baseline $+30,+60$ and +100 yr). Preliminary results of the simulations for 25 Nordic catchments are described hy Sælthun et al. (1994a, b).

\section{NATURAL CIIMATE VARIABILITY}

The climate of the earth is characterized by natural variability on all time scales ranging from the diurnal cycle to millions of years. Variability on the longest time scales (>1000 yr) is related to changes in solar radiation, the configuration of continents and oceans, time-dependent changes in the orbit of the earth around the sun (precession, obliquity, eccentricity), and changes in the chemical composition and optical properties of the atmosphere. Variability on a severalyear time scale appears to be dominated by natural variability of the atmosphere, but variability on decadal and century-long time scales is most likely caused by the internal variability of the coupled oceanatmosphere system, and is possibly influenced by anthropogenic effects during this century. Climate changes caused by increasing concentrations of $\mathrm{CO}_{2}$ and other trace gases in the atmosphere during the next decades will be superimposed on the natural variability of the ocean-atmosphere system. This prevents an unequivocal detection of greenhouse warming until the temperature has risen significantly above the range of natural climatological variability.
Global mean surface air temperature of the earth has increased by 0.3 to $0.6^{\circ} \mathrm{C}$ in the course of the last $100 \mathrm{yr}$ (IPCC 1992). This warming is consistent with transient climate model computations, but it is also of the same magnitude as natural climate variability.

Climate variability on decadal time scales is larger in the North Atlantic region than in most other regions of the earth. Temperature in the North Atlantic region over the last 100 yr has fluctuated by as much as 1.0 to $1.5^{\circ} \mathrm{C}(10 \mathrm{yr}$ means), but the variation of temperature with time has been far from a uniform increase. In the decades from 1961 to 1990 , a relatively strong cooling trend dominated climate development in the North Atlantic region (Chapman \& Walsh 1993). The maximum cooling (ca $0.5^{\circ} \mathrm{C}$ ) was located south and west of Iceland and Greenland, but the cooling extended over most of the North Atlantic Ocean and Scandinavia. The amplitude and spatial distribution of the observed cooling are surprisingly similar to modelled temperature fluctuations arising randomly in this region on a time scale of approximately $50 \mathrm{yr}$ in coupled oceanatmosphere GCMs (Delworth et al. 1993, Weisse et al. 1993). The model computations indicate that variability on decadal and longer time scales in the North Atlantic region is highly influenced by variations in the thermohaline circulation of the North Atlantic Ocean, which are related to the so-called North Atlantic Oscillation (cf. Lamb \& Peppler 1987). The thermohaline circulation in the North Atlantic Ocean is a part of a larger circulation system, the 'conveyor belt'. Deep water formed in the North Atlantic sinks and flows southward into the Pacific via the Southern Circumpolar Ocean. It upwells in the North Pacific and is carried back into the Atlantic in the upper ocean. The 'conveyor belt' is thought to have played a major role in the extreme climate fluctuations of the last ice age (Broecker et al. 1985). The thermohaline circulation of the oceans is believed to operate in at least 2 semisteady states, one with deep water formation taking place in the North Atlantic as described above, and the other without this deep water formation (e.g. Källén \& Huang 1987). These different steady states arise 'naturally' in coupled ocean-atmosphere GCMs, and the GCM experiments indicate that temperature in the North Atlantic region would be up to $8^{\circ} \mathrm{C}$ lower without the northward heat transport associated with the deep water formation (Manabe \& Stouffer 1988). An understanding of the dynamics of the thermohaline circulation appears to be vital for assessing greenhousegas-induced temperature changes in the North Atlantic region, but these dynamics are still not adequately described in present-day ocean models used for climate studies.

It appears likely that the climate system of the North Atlantic region is currently returning from the rela- 
tively cool period between 1961 and 1990. If this conceivably 'natural' return to warmer conditions has a similar amplitude and time scale as the recent cool period, then the associated 'natural' climate fluctuation will be of a similar magnitude as the warming implied by most GCM-derived climate change scenarios for this region in the next decades. Transient coupled ocean-atmosphere GCMs indicate, furthermore, that climate changes due to increasing concentrations of $\mathrm{CO}_{2}$ and other trace gases in the atmosphere might lead to significant changes in the thermohaline circulation of the North Atlantic Ocean (Cubasch et al. 1991 1992b. Manabe et al. 1991). The large natural variability of the thermohaline circulation on decadal time scales and the complex coupling between this circulation and conceivable $\mathrm{CO}_{2}$-induced climate warming in the North Atlantic region will make it very difficult to differentiate between anthropogenic variability in the climate system and natural climate variability in this region for the next 20 to $30 \mathrm{yr}$.

\section{REVIEW OF GLOBAL CLIMATE CHANGE COMPUTED BY GENERAL CIRCULATION MODELS}

\section{Background}

Studies of global warming using GCMs have improved dramatically in the last few years as these models have become more sophisticated both physically and computationally. The ability of the models to simulate present climate on large scales has improved and methods are being developed to simulate regional climate.

The major advances in GCM studies of global warming in the past few years have been transient simulations and coupled ocean-atmosphere models. Transient simulations describe the temporal evolution of the climate of the earth as the effective $\mathrm{CO}_{2}$ content of the atmosphere is gradually increased, typically at an annual rate close to $1 \%$. Coupled ocean-atmosphere models consist of 2 components, an atmospheric and an oceanic one, which are coupled together by fluxes of heat, water, and momentum through the surface of the ocean. In spite of these advances, confidence in regional climate predictions based on the direct output of the most advanced simulations of coupled, transient GCMs remains low.

A comparison of a large number of GCMs is presented by Boer et al. (1992), who assess the ability of the models to simulate the present climate, and by Randall et al. (1992), who compare the response of the surface energy budget and the hydrological cycle of the models to an imposed sea surface temperature perturbation.

\section{Mixed layer models}

Until recently, GCM studies of the greenhouse effect have been carried out using an extremely simple representation of the world's oceans. Consequently, the dynamic interaction of the atmosphere and the oceans is far from realistic in these studies. The ocean is modeled as a well-mixed layer with thickness on the order of $50 \mathrm{~m}$. Horizontal oceanic heat transport is most often prescribed and remains unchanged during the simulations. Heat exchange with the deeper ocean is either prescribed or computed from an effective heat diffusion coefficient between the mixed layer and the deeper ocean. An example of such a study is found in Hansen et al. (1988), who reference a number of other studies with mixed layer models. The main conclusions of these studies are:

(1) The equilibrium sensitivity of global mean surface temperature to a doubling of the effective $\mathrm{CO}_{2}$ content of the atmosphere is between 2 and $5^{\circ} \mathrm{C}$.

(2) The warming increases more or less uniformly towards the poles. The warming north of $60^{\circ} \mathrm{N}$ and south of $60^{\circ} \mathrm{S}$ is about double the warming close to the equator.

(3) Away from the equator, the warming is greater during winter than during summer.

Hansen et al. (1988) performed a transient simulation using a mixed layer ocean model with fixed horizontal oceanic heat transport. The computed transient warming, under a $1 \%$ per year increase in the effective concentration of greenhouse gases, was about $0.3^{\circ} \mathrm{C}$ per decade. This rate was not established until after a few decades of somewhat slower warming.

GCMs of the atmosphere coupled with a mixed layer ocean represent the geographical variation of the current climate reasonably well, but they underestimate long-term climatic variability, especially on decadal time scales. The low climatic variability of mixed layer GCMs is related to their extremely simple representation of the oceans, which are an important source of climatic variability.

\section{Coupled ocean-atmosphere models}

In coupled ocean-atmosphere models, ocean currents, horizontal and vertical transport of heat and salinity in the ocean, and heat, vapour and momentum exchange between the atmosphere and the ocean are explicitly computed. The coupled models usually employ flux adjustments in order to maintain a realistic equilibrium state (Sausen et al. 1988). The flux adjustments are used to correct the fluxes of water and heat through the oceanic surface by an amount that varies 
geographically but does not change during the simulation. GCM experiments with increased computational resolution are being carried out with the aim of eliminating the need to employ flux adjustments. Transient, coupled GCM simulations have been carried out at:

- National Center for Atmospheric Research, NCAR, Boulder, Colorado, USA (Washington \& Meehl 1989, Meehl et al. 1993)

- Geophysical Fluid Dynamics Laboratory, GFDL, Princeton, New Jersey, USA (Manabe et al. 1991, 1992)

- Max-Planck-Institut für Meteorologie, MPI, Hamburg, Germany (Cubasch et al. 1991, 1992a)

- Hadley Centre, UK Meteorological Office, UKMO, Bracknell, UK (Murphy 1992, 1995, Murphy \& Mitchell 1995).

These simulations are summarized in IPCC (1992) (computational resolution, cloud description, flux adjustments and length of simulation are given for each simulation). The NCAR simulation, which is the only one that does not employ flux adjustments, has recently been extended from 30 to $60 \mathrm{yr}$. The other coupled simulations listed above are $100 \mathrm{yr}$ long. The control experiments of the models deviate significantly from the real climatology if flux adjustments are not used (cf. Manabe et al. 1991). The use of flux adjustments is, however, problematic in principle, and model results must be viewed with some reservations for regions such as the North Atlantic where the magnitude of the flux adjustments is similar to the magnitude of the ocean/atmosphere fluxes themselves. The coupled studies have lead to new, surprising insights into the dynamics of the oceans, and they underscore the importance of ocean-atmosphere interaction for climate changes (e.g. Manabe \& Stouffer 1988).

After an initial period of relatively slow warming, which is present in some of the simulations (e.g. MPI, NCAR) but not in others (e.g. GFDL), the transient warming rate, when concentration of greenhouse gases in the atmosphere increases by about $1 \%$ per year, is approximately $0.3^{\circ} \mathrm{C}$ per decade for all the models. The NCAR simulation published in Washington \& Meehl (1989) spans only 30 yr and gives a somewhat lower rate of warming. A recently published $30 \mathrm{yr}$ extension of this simulation (Meehl et al. 1993) shows that the rate of warming for years 23 to 60 of the combined simulation is about $0.3^{\circ} \mathrm{C}$ per decade.

The warming is greatest at high latitudes during the winter, which is in agreement with results from mixed layer models. However, the warming is substantially reduced over the Circumpolar Ocean of the Southern Hemisphere and over the northern North Atlantic due to vertical mixing in the ocean. This effect is not present in the mixed layer models. For the North Atlantic, the reduced warming may partly be due to a change in quasi-stationary waves in the atmosphere which are introduced by differential heating of ocean and land areas (Kaas 1993c). The amplitude of the local minimum in the warming in the northern North Atlantic varies between the models. It is strongest in the MPI model, which shows little warming in the area south of Greenland and Iceland at the end of the $100 \mathrm{yr}$ long simulation. According to the GFDL model, warming in the northern North Atlantic is relatively close to the global average warming and slightly lower than the average warming of other ocean-covered areas. This warming is about half of the warming found by the GFDL model in the latitude range of the northern North Atlantic. The NCAR model does not predict lower warming over the northern North Atlantic compared to other ocean-covered areas after the initial 30 yr period of relatively slow warming is over

The main conclusions of the coupled GCM studies are:

(1) The estimated climatic sensitivity of global mean temperature to a doubling of the effective $\mathrm{CO}_{2}$ content, and the transient warming rate under a $1 \%$ per year increase in the effective $\mathrm{CO}_{2}$ content, are in agreement with the previous results of mixed layer models, i.e. 2 to $5^{\circ} \mathrm{C}$ and approximately $0.3^{\circ} \mathrm{C}$ per decade, respectively.

(2) There is less warming over the oceans than over land à̃êas.

(3) The spatial pattern of the warming over the globe does not change significantly after the first few decades of the simulations (except perhaps in the NCAR model).

In spite of the general agreement between the coupled models with regard to the above conclusions, there are large discrepancies between the models, especially in regional predictions of the warming. The location and strength of local minima in the warming in the northern North Atlantic and the Circumpolar Ocean of the Southern Hemisphere are different in the different simulations, and local differences in the warming after 50 to 100 model years are higher than 2 to $3^{\circ} \mathrm{C}$ in many places. Changes in precipitation rates are believed to be much more uncertain than temperature changes, although there is some consensus among the models that precipitation rates will increase by a few percent for each degree of warming.

Additional coupled model runs have been completed at some of the modelling centers since the runs described above were carried out. Transient results from a number of coupled and mixed layer models in the Nordic area, including recent results from a model run at MPI, are described in J, Räisänen (1994). Recently an intercomparison between results from 
several different GCMs has been carried out by IPCC Working Group II. Transient coupled model results from GFDL, MPI and UKMO were considered. Results from these simulations are available on computer diskettes (Greco et al. 1994), but a report summarizing the results and discussing their uncertainty is not yet available. A preliminary investigation of the intercomparison results does not reveal any startling disagreements with the older model results discussed above, and the uncertainty regarding modelled precipitation still exists.

\section{Radiation and clouds in general circulation models}

The energy balance of the earth is to a large extent governed by an interaction between the optical properties of clouds and radiative processes. In addition, clouds are associated with the heating of the lower parts of the atmosphere through sensible and latent heat transport. On a global average, clouds are responsible for $82 \mathrm{~W} \mathrm{~m}^{-2}$ in terms of latent heat release to the atmosphere and $58 \mathrm{~W} \mathrm{~m}^{-2}$ in terms of the reflection of short-wave incoming solar radiation. About $14 \mathrm{~W} \mathrm{~m}^{-2}$ of the incoming solar radiation is absorbed by clouds, and the net long-wave effect of clouds, water vapour, ozone, carbon dioxide, and other greenhouse gases, gives a surface temperature which is $33 \mathrm{~K}$ higher than it would have been without clouds and greenhouse gases. It is difficult to distinguish between the longwave radiative effects of clouds and the greenhouse gases, as the fluxes are not additive but nonlinearly interdependent. By comparing the basic heat fluxes associated with clouds with the total incoming shortwave radiative flux $\left(342 \mathrm{~W} \mathrm{~m}^{-2}\right)$, one immediately realizes the significance of clouds. A major shortcoming of present-day climate models is their inability to model clouds and their radiative properties in a satisfactory manner (IPCC 1992). A comparison with the net computed direct radiative effects of a doubling of atmospheric $\mathrm{CO}_{2}$ content $\left(4 \mathrm{~W} \mathrm{~m}^{-2}\right)$ also highlights the importance of a correct treatment of clouds and their radiative properties in a climate model

The standard method of treating clouds in a climate model is to assume that their optical properties are directly related to the relative humidity. This treatment is relatively cheap in terms of the computing power needed to perform a climate simulation, but it has several drawbacks. It is obvious that the liquid water and ice content of a cloud heavily influences radiative transfer calculations and that the relative humidity of air is not sufficient to determine the cloud properties. It has been shown that climate simulations are very sensitive to this particular aspect of cloud treatment, and Mitchell et al. (1989) demonstrate how sensitive the atmospheric response to a doubling of the $\mathrm{CO}_{2}$ content is to the description of clouds. They compare a standard relative humidity scheme with a more sophisticated one in which the cloud water content is calculated explicitly. The sensitivity to a doubling of the $\mathrm{CO}_{2}$ content was reduced by more than a factor of 2 when computed as a global average. The GCMs used here for scenario calculations differ in this respect. The GFDL model as described by Manabe et al. (1991, 1992) does not explicitly calculate the cloud liquid water, while in the MPI model (Roeckner et al. 1992) the cloud water budget is calculated and this cloud water is used in the radiation calculations. It has been argued (Lindzen 1991) that the high cirrus clouds in the tropics are a particular source of sensitivity; both the assumed ice content and the actual form of the ice particles (Takano et al. 1992) have a very large influence on the radiative fluxes.

In addition to the feedback between clouds and radiation, clouds are also responsible for a large fraction of the heat transport between the earth's surface and the atmosphere. This is accomplished through latent heat release, a process which must be parameterized in a climate model. The latent heat transport is particularly strong in the tropics and it has been shown that climate models are sensitive to the way in which this parameterization is formulated. Two different ways of formulating the cloud latent heating were compared in a $\mathrm{CO}_{2}$ doubling experiment. The warming found for the 2 schemes was markedly different, particularly in tropical regions (IPCC 1990). The experiments differed almost by a factor of 2 in terms of the tropical temperature anomaly.

Radiative fluxes must also be parameterized in a climate model. The electromagnetic spectrum has to be divided into a number of wavelength bands, and the absorption and emission rates must be calculated over finite model layers. The optical properties of the various atmospheric constituents have to be specified as functions of concentrations, air pressure, solar angle, etc. Radiative flux computations are very computer intensive, and the design of such computations involves a compromise between model efficiency and accuracy. There are many ways of achieving this compromise, and several schemes have been proposed over the years. A comparison between some of the most popular schemes and some very accurate reference calculations has been made by Ellingson et al. (1991). They found that the radiative flux computations produced quite a scatter, given the same atmospheric background conditions. Given a clear sky with a standard atmospheric vertical temperature profile, the standard deviation of the long-wave flux at the surface was as large as $12 \mathrm{~W} \mathrm{~m}^{-2}$ This can be compared with the previously mentioned direct radiative effect of a doubled $\mathrm{CO}_{2}$ content which is only $4 \mathrm{~W} \mathrm{~m}^{-2}$. Recently, 
P. Räisänen (1994) performed similar tests with the radiation schemes used in European GCMs. Räisänen also showed the drastic differences which occur in the radiative treatment of clouds using the different radiation schemes.

The various sensitivities discussed in this section may lead one to think that present-day climate models are completely useless for calculating climate sensitivity to, for example, a doubling of the $\mathrm{CO}_{2}$ content. This is not the case, but one should be very cautious when interpreting the results. The first objective of any climate model is that it be able to simulate the present climate with reasonable accuracy. Given that the various parameterizations and other approximations in the model lead to errors, a certain amount of tuning is necessary. This is often accomplished through a variation of diffusion parameters. Eliasen \& Laursen (1990) have shown that alternative ways of formulating horizontal diffusion give markedly different results, and that the model climate is very much controlled by the diffusion parameters. One is thus forced to apply some tuning through the horizontal diffusion scheme, and in the tuning process it may well be that errors in various schemes compensate for each other. This will still give us a reasonable model climate but the effects it may have on perturbed climate simulations are unpredictable. For this reason, a comparison between different climate scenario computations done with different models is essential, and if all models give similar results one may have added confidence in the result as compared to a simulation with only one climate model. Increases in computing capacity will also give rise to increased confidence in model computations as added horizontal and vertical resolution make it possible to increase the accuracy of, for instance, the radiative flux calculations and the complexity of the cloud description, thereby improving model performance.

\section{The 'cold start' problem}

Some transient model simulations show a somewhat reduced rate of climatic warming during the first few decades of the simulations. The slow initial warming is believed to be related to a so-called 'cold start' problem of GCM simulations which leads to an artificial, slow rise in the temperature during this period (Cubasch et al. 1992a, 1994. Hasselmann et al. 1993, Meehl et al. 1993). The significance of the initial slow warming for predictions of future climate must be viewed with a certain 'starting point' of the increase in the effective $\mathrm{CO}_{2}$ concentration in the atmosphere in mind. The rise in the effective $\mathrm{CO}_{2}$ concentration of the atmosphere accelerated around 1960. Some modellers use the year 1958 (when $\mathrm{CO}_{2}$ measurements at Mauna
Loa, Hawaii, USA, were started) as a starting point when discussing the climate changes computed by their GCMs (e.g. Hansen et al. 1988, Stouffer et al. 1989), whereas others (e.g. Cubasch et al. 1991, 1992a) use a starting point between 1980 and 1990. The former approach seems more sensible for most currently available coupled GCM simulations which do not explicitly account for buildup of $\mathrm{CO}_{2}$ before the start of the computations. This implies that even if the initial period of slow warming simulated by such GCMs is taken as a valid prediction, it should already be over by now and future warming rates should be estimated as the simulated GCM warming after an initial period of approximately $30 \mathrm{yr}$ is over. As mentioned above, the available transient coupled GCM simulations indicate that this warming rate is approximately $0.3^{\circ} \mathrm{C}$ per decade, which is in agreement with the estimate of IPCC (1990, 1992). Recently, a coupled model experiment starting at an early stage of industrialization, i.e. 1935, was performed (Cubasch et al. 1994), and some authors have begun correcting the results from model runs started with present equivalent $\mathrm{CO}_{2}$ levels to compensate for the effects of the 'cold start' (cf. Cubasch et al. 1992a, b, Hasselmann et al. 1993). These studies indicate a warming rate close to $0.3^{\circ} \mathrm{C}$ per decade from 1990 onwards for transient experiments.

\section{GCM results for the Nordic area}

Some coupled ocean-atmosphere GCM simulations indicate that $\mathrm{CO}_{2}$-induced warming is substantiaily reduced in the northern North Atlantic region compared to the warming that would occur in this region in the absence of vertical mixing in the ocean. In spite of the low confidence in regional GCM model predictions, this effect seems to be real, and should lead to reduced warming in the Nordic countries. The computed warming has a minimum south of Iceland or Greenland and increases towards continental Europe. The warming in the northern North Atlantic would be substantially above the global average (by a factor of ca 1.5 to 2) in the absence of this effect because the warming generally increases towards the poles. The local minimum in the warming in the northern North Atlantic is not particularly strong in the NCAR simulation, and in the GFDL simulations the warming in the northern North Atlantic is similar to the global average, but the local minimum in the MPI and UKMO simulations is almost zero. In the MPI, GFDL and UKMO simulations, the warming in northern Scandinavia and Finland is somewhat above the global average. There seems to be considerably more uncertainty in the model results in and near the northern North Atlantic Ocean than in most other parts of the world. 
In view of the great effect of ocean dynamics on the warming near the North Atlantic in coupled oceanatmosphere GCM simulations, it seems clear that results from mixed layer GCM simulations cannot be used to estimate $\mathrm{CO}_{2}$-induced climate changes in this area. Conclusions based on such models, e.g. increasing warming towards the poles, higher warming in the winter than in the summer and a greater increase in winter precipitation than in summer precipitation, are therefore not directly applicable when estimating climate changes in this region.

Currently available coupled ocean-atmosphere simulations indicate that the rate of $\mathrm{CO}_{2}$-induced warming might be similar or somewhat lower than a global average of approximately $0.3^{\circ} \mathrm{C}$ per decade in Iceland, in southern Greenland and along the west coast of Norway and Denmark. The warming in other parts of the Nordic countries could, on the other hand, be somewhat higher than the global average, i.e. more in line with other areas in the latitude range of the Nordic countries. The GFDL results indicate that the warming in the northern North Atlantic and in Scandinavia will not be as seasonally dependent as elsewhere in the latitude range of the Nordic countries, i.e. the warming will be similar for both summer and winter. Very little can be said about precipitation changes directly on the basis of the output of the coupled GCMs, except that it is likely that precipitation will increase, perhaps by ca $5 \%$ for each degree of warming in the latitude range of the Nordic countries.

\section{DERIVATION OF REGIONAL CLIMATE CHANGE FROM GENERAL CIRCULATION MODEL OUTPUT}

Confidence in regional climate predictions based directly on the output of the most advanced transient coupled GCM simulations remains low in spite of the important improvements in GCM computations in the past few years. However, it is widely accepted that present-day GCMs are able to simulate the global large-scale state of the atmosphere in a reasonable manner. It is estimated that GCM results are unreliable on spatial scales shorter than about 4 to 8 times the spatial resolution in the models' computations. This corresponds to approximately 2000 to $4000 \mathrm{~km}$ for current GCM simulations. It is desirable to be able to make climate predictions on shorter scales than this, especially in regions where spatial gradients in the predicted climate changes may be large and in areas where orographic effects on the climate are important. Both effects are important for the Nordic countries.

GCM results can be interpolated to shorter spatial scales using a nested approach or statistical methods. In the nested approach, a regional climate model is driven with the large-scale flow computed by the GCM. This has, among other things, the advantage that the orography of the region under consideration can be represented much more accurately than is possible in the GCM itself. Meteorological processes which are orographically controlled, e.g. orographic precipitation, can thus be much better resolved, which is especially important for assessing the hydrological impact of the computed climate changes. Examples of studies of this kind are found in Giorgi et al. (1992) and Marinucci \& Giorgi (1992).

In the statistical approach, empirically determined correlations between the observed regional climate and the corresponding observed large-scale atmospheric flow are used to estimate the regional climate corresponding to the large-scale atmospheric flow pattern computed by the GCM. Examples of studies of this kind are found in Karl et al. (1990), Hewitson \& Crane (1992) and von Storch et al. (1993). These studies show considerable promise in predicting local surface parameters which are unreliable in the unprocessed gridpoint output of the GCMs. The work of von Storch et al. (1993) is specifically directed at regional precipitation.

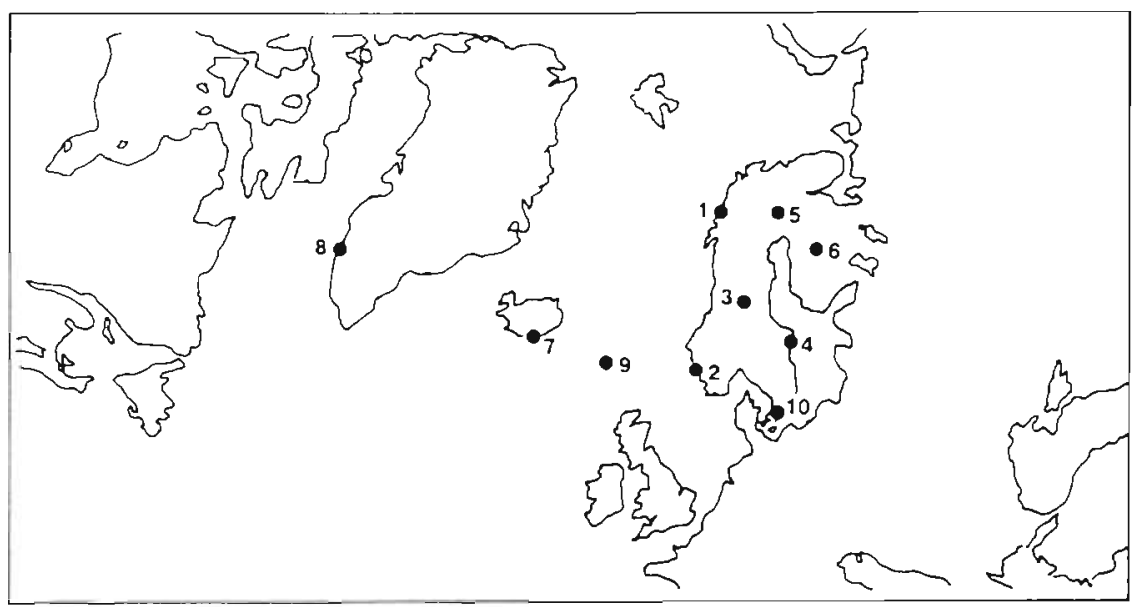

Fig. 1. Location of the climatological stations used in the statistica]. analysis: (1) Tromso, (2) Bergen, (3) Östersund, (4) Stockholm, (5) Sodankylä, (6) Kuopio, (7) Kirkjubæjarklaustur, (8) Nuuk/Godthåb. (9) Thorshavn, (10) Copenhagen 
It shows that the simulation of the present climate is very much improved by these statistical considerations, and also that the $\mathrm{CO}_{2}$-induced precipitation changes computed by the statistical approach are significantly different from the precipitation changes computed on the basis of GCM grid-point values.

In spite of the considerable promise offered by the downscaling methods discussed above, they depend critically on the quality of the large-scale flow of the GCM. Errors due to flux adjustments, gravity wave drag, sea ice representation, cloud parameterization and other known problematic aspects of GCMs will influence the downscaled results. In addition, climate change computations based on statistical downscaling depend on the assumption that the statistical relationship between local climate and large-scale circulation will not change in the changed climate. The statistical methods do, however, partly correct for the large-scale systematic model errors observed in the control experiments as long as these errors are similar in both the control and the transient experiments. Furthermore, some other problematic aspects, caused by coarse model resolution, unrealistic orography, and omission of various other local effects, will be improved. Nevertheless, the results from downscaling must be considered with caution until significant improvements in the large-scale GCM results are realized.

\section{STATISTICAL DOWNSCALING FOR CLIMATO- LOGICAL STATIONS IN THE NORDIC COUNTRIES}

\section{Background}

In order to estimate local climate changes in the Nordic region a statistical downscaling study of this region was carried out by Kaas (1993a, b, 1994). Climate changes were computed at 10 climatological stations in the Nordic countries based on coupled oceanatmosphere results from the MPI. The stations are shown in Fig. 1. The GCM results from the MPI were used because they were readily available at the time the study was initiated, and the MPI model appeared to be no better or worse than other coupled GCM models in use at that time.

The atmospheric component of the model (ECHAM1) is a low resolution version of the spectral numerical weather forecasting model of the European Centre for Medium Range Weather Forecasts which has been modified at the Meteorological Institute of the University of Hamburg and the MPI. The horizontal resolution is limited by a triangular spectral cutoff at total wave number 21 . The model has 19 vertical levels in a hybrid $\sigma$-p system. The ocean component (LSG) has 11 variably spaced vertical levels and 2 overlapping $5.6^{\circ} \times$ $5.6^{\circ}$ horizontal grids. The atmosphere and ocean components are coupled by the air-sea fluxes of momentum, heat and water using flux-adjustments to prevent undesirable drift in the control simulation. Further description of the model is given in Cubasch et al. (1992a) and in a number of reports available from MPI (cf. Roeckner et al. 1992).

\section{The control simulation}

The results of the MPI model in the North Atlantic region are compared to observations in Kaas (1993a). It is found that there are large systematic errors in the $500 \mathrm{hPa}$ height and in the mean sea level pressure of the control run compared to NMC (U.S. National Meteorological Center) analyses of the North Atlantic region. The $500 \mathrm{hPa}$ height during the winter season in the model has a much too weak north-south gradient and indicates a NW wind direction over most of the region instead of the $\mathrm{SW}$ wind direction prevailing in the NMC analyses. The Icelandic low in the model winter sea level pressure field is displaced far to the southwest due to defective gravity wave drag parameterization (cf. Roeckner et al. 1992). Consequently, near-surface wind direction is easterly instead of westerly over much of Europe and the North Atlantic Ocean. It therefore appears that the large-scale atmospheric flow in the model in the North Atlantic region is not particularly realistic. This violates the basic assumption of the statistical downscaling technique as described in the previous section. The climatology of the modelled large-scale atmospheric flow has become more realistic in recent GCMs with increased computational resolution. Results of full transient coupled experiments with these models are, however, not available at the time of this writing. Although the results of the statistical downscaling described here must be viewed with some reservations due to the above-mentioned deficiencies of the control climatology, the statistical method is sound and presumably will produce more reliable results when applied to improved GCM simulations as they become available. Despite its limitations, the statistical analysis was carried out in order to see whether climate changes computed by the downscaling would differ much from changes derived directly from grid-point values. A comparison of the Arctic climate in 5 atmospheric GCMs (Walsh \& Crane 1992) indicates that other GCMs which have been used for climate change experiments are afflicted with similar problems in the North Atlantic region, although the GFDL model appears to perform significantly better than the other models in this area. The comparison made by J. Räisänen (1994) also indicates that the GFDL model per- 
forms relatively well in the Nordic area, although a recent run from MPI (Lunkeit et al. 1994) using a different oceanic component (OPYC) and an improved atmospheric component (ECHAM2) performs even better in some respects.

\section{Statistical method}

The statistical method is based on a regression analysis which relates observed monthly mean values of meteorological variables at climatological stations to an EOF (Empirical Orthagonal Function) decomposition of the monthly mean large-scale atmospheric flow (Kaas 1993b). The predictive variables are $500 \mathrm{hPa}$ heights or the average of the 500 and $1000 \mathrm{hPa}$ heights (representing pressure) and the 500-1000 hPa thickness (representing temperature) from NMC analyses in the time period 1961 to 1987 . The regression explains 90 to $95 \%$ of the variance of observed mean monthly winter temperatures and 80 to $95 \%$ of the variance of the summer temperatures. Precipitation was more difficult to reproduce: the regression explains 70 to $90 \%$ and 50 to $80 \%$ of the observed variance in the winter and summer precipitation, respectively.

The regression model, which was derived from station observations and NMC analyses, is applied to computed circulation changes from the last 30 yr of the MPI model runs (i.e. transient run vs control run). This procedure yields statistical estimates of changes in modelled predictands at the stations, e.g. surface temperature and precipitation, based on the assumption that the estimated relations between predictors and predictands do not change. The $30 \mathrm{yr}$ period is centered around year 85 of the transient run. Therefore, the estimates apply to approximately the middle of the next century if one assumes that the 'cold start' problem leads to a 20 to 25 yr retardation of the MPI model response.

\section{Downscaling results}

Results of the statistical downscaling for temperature and precipitation changes for the 10 Nordic climatological stations are summarized in Table 1 . The table lists the results for the summer and winter seasons only. Kaas (1993b, 1994) gives full results for all 4 seasons of the year, including computed changes in the diurnal temperature range which are omitted below. Temperature changes are given in ${ }^{\circ} \mathrm{C}$ and precipitation in percentages. Kaas derived 2 sets of computed changes using slightly different statistical methods. In Kaas (1993b), the $500 \mathrm{hPa}$ height and the 500-1000 hPa thickness are used as predictors, and the statistical analysis is performed independently for each season of the year. In Kaas (1994), the average of the 500 and $1000 \mathrm{hPa}$ heights (instead of the $500 \mathrm{hPa}$ height) and the 500-1000 hPa thickness are used as predictors, and the yearly cycle is removed from the observed predictors and predictands before calculation of the regression coefficients. There are some further differences between the methods which are described in detail in Kaas (1994).

Kaas (1994) applied a Monte Carlo technique to estimate the statistical uncertainty of his computed changes at the 95\% significance level. This uncertainty arises from the effect of the statistical uncertainty in the regression coefficients on the computed climate changes. Uncertainty in the long-term mean difference between the transient and control runs of the climate model is, however, not accounted for. Furthermore, uncertainty due to possible effects of the

Table 1. Temperature and precipitation changes computed by statistical downscaling of transient GCM output from MPI for 10 Nordic climatological stations. The changes correspond to approximately the middle of the next century and they should be interpreted with respect to a 1961 to 1990 baseline. Results from Kaas (1993b) are indicated with a subscripted '1', those from Kaas (1994) with a subscripted '2'

\begin{tabular}{|c|c|c|c|c|c|c|c|c|}
\hline \multirow[t]{3}{*}{ Station } & \multicolumn{4}{|c|}{ Temperature changes $\left({ }^{\circ} \mathrm{C}\right)$} & \multicolumn{4}{|c|}{ Precipitation changes (\%) } \\
\hline & \multicolumn{2}{|c|}{ Winter } & \multicolumn{2}{|c|}{ Summer } & \multicolumn{2}{|c|}{ Winter } & \multicolumn{2}{|c|}{ Summer } \\
\hline & $\Delta \mathrm{T}_{1}$ & $\Delta \mathrm{T}_{2}$ & $\Delta \mathrm{T}_{\mathrm{l}}$ & $\Delta \mathrm{T}_{2}$ & $\Delta \mathrm{P}_{1}$ & $\Delta \mathrm{P}_{2}$ & $\Delta P_{i}$ & $\Delta \mathrm{P}_{2}$ \\
\hline Tromse & 4.2 & 4.7 & 2.8 & 2.3 & 38 & 28 & 40 & 51 \\
\hline Bergen & 3.4 & 3.5 & 1.2 & 0.5 & 30 & 30 & 17 & 26 \\
\hline Östersund & 5.7 & 7.3 & 1.6 & 3.0 & 8 & -46 & 8 & -11 \\
\hline Stockholm & 5.5 & 5.7 & 1.2 & 3.3 & 43 & -35 & 20 & -10 \\
\hline Sodankylä & 7.2 & 9.0 & 1.5 & 4.1 & -19 & 0 & 5 & -5 \\
\hline Kuopio & 6.7 & 6.9 & 1.7 & 4.1 & 37 & -11 & 24 & 22 \\
\hline Kirkjubæjarklaustur & 1.7 & 2.2 & 1.3 & 0.2 & 4 & 64 & 20 & 53 \\
\hline Nuuk/Godthåb & 2.0 & -3.4 & 1.1 & -2.1 & 9 & 6 & 13 & 79 \\
\hline Thorshavn & 2.1 & 2.7 & 1.3 & 0.9 & 20 & 1 & -4 & 0 \\
\hline Copenhagen & 3.1. & 2.8 & 1.5 & 2.1 & 6 & -41 & -4 & -64 \\
\hline
\end{tabular}


unrealistic large-scale flow of the climate model on the computed changes is not included in this estimate. The statistical uncertainty varies among the stations. It is $\pm 0.5^{\circ} \mathrm{C}$ to $\pm 2^{\circ} \mathrm{C}$ for the temperature changes, but for the precipitation changes it is on the same order as the precipitation changes themselves, except that the precipitation changes in Tromsø, Bergen, Kirkjubæjarklaustur and Copenhagen in winter are statistically significant.

\section{Evaluation of the results and assessment of uncertainty}

With the exception of $\Delta \mathrm{T}_{2}$ for Nuuk/Godthåb, the downscaled temperature changes are in relatively good agreement with grid-point values from coupled ocean-atmosphere GCMs in this region. This agreement shows that surface temperature changes derived from GCM grid-point values are in fact fairly consistent with computed changes in the large-scale atmospheric flow. Temperature changes during the winter are greatest in Finland and in northern Norway and Sweden, but smaller in Greenland, Iceland and the Faeroe Islands. Temperature changes in the summer season are smaller and more uniform over the region. The corresponding warming rates are approximately 0.2 to $0.3^{\circ} \mathrm{C}$ per decade during the summer season when retardation due to 'cold start' is taken into account. During the winter season, the warming rates vary from approximately $0.3^{\circ} \mathrm{C}$ per decade in the western part of the area to over $1^{\circ} \mathrm{C}$ per decade in the eastern part. The negative $\Delta T_{2}$ values for Nuuk/Godthåb are difficult to explain, but it appears that the regression model for Nuuk/Godthåb is not as well determined as for the other stations. Furthermore, Nuuk/ Godthåb lies relatively close to the western edge of the computation domain and this may have adversely affected the regression model for this station. The magnitude of the differences between the changes computed by the 2 methods is similar to the statistically determined uncertainty of the computed values (except for $\Delta T_{2}$ for Nuuk/Godthåb) and we are inclined to take them as indicators of uncertainty rather than preferring one method to the other.

Changes in precipitation vary strongly from station to station and from season to season, as would be expected from the high statistically determined uncertainty of the estimated changes. On average the relative increase in precipitation is positive by ca $10 \%$, which is similar to the zonally averaged increase in precipitation at the latitude of the Nordic countries according to some coupled ocean-atmosphere GCMs (e.g. Manabe et al. 1991). Irregular distribution of computed changes in precipitation is not uncommon in cli- mate change studies (e.g. Marinucci \& Giorgi 1992) and is partially due to the inherent internal variability of precipitation which to some extent is reflected in the model results. It is difficult to draw any firm conclusions about future changes in precipitation from these results. Therefore, precipitation changes are highly uncertain, but they may be slightly positive when averaged over long time periods and large areas.

\section{CLIMATE CHANGE SCENARIOS FOR THE NORDIC COUNTRIES}

To construct a climate change scenario for the Nordic countries, we used information from GCM runs as well as the statistically derived downscaled information described in the previous section. The overall consistency between direct GCM model output and the statistically derived temperature response gives us increased confidence in the model-derived temperature increase. For precipitation there is a large degree of uncertainty and we have attempted to subjectively weigh the direct model output together with the results from the statistical method. We must also bear in mind that both sources are affected by possible errors in the sensitivity of the climate models to an increase in the greenhouse gases, and the statistical technique does not correct for this. Furthermore, both sources are affected by systematic errors in the large-scale flow, and the statistical technique cannot be expected to fully correct for this in view of the magnitude of the errors in the climatology of the control experiment. We rely quite heavily on direct model output from the GFDL model, as results from this model seem to be more realistic than other published GCM results for the North Atlantic area (Walsh \& Crane 1992, J. Räisänen 1994). The scenario produced is partly based on subjective judgment and is therefore of the composite type as discussed above in the section 'Climate change scenarios'.

The downscaled summer warming agrees relatively well with GCM results, except that the GFDL model predicts a somewhat higher warming over the North Atlantic Ocean than is derived by the statistical procedure. The downscaled winter warming in Finland and Scandinavia is, on the other hand, somewhat greater than suggested by the GDFL model in that area. The scenario specifies a warming rate of $0.3^{\circ} \mathrm{C}$ per decade $\left(0.35^{\circ} \mathrm{C}\right.$ per decade in winter and $0.25^{\circ} \mathrm{C}$ per decade in summer) for the western part of the area, increasing to $0.45^{\circ} \mathrm{C}$ per decade $\left(0.6^{\circ} \mathrm{C}\right.$ per decade in winter and $0.3^{\circ} \mathrm{C}$ per decade in summer) in Finland, northern Norway and Sweden. A sinusoidal variation with time between the summer and winter values is assumed. Fig. 2A shows the temperature change scenario. This 

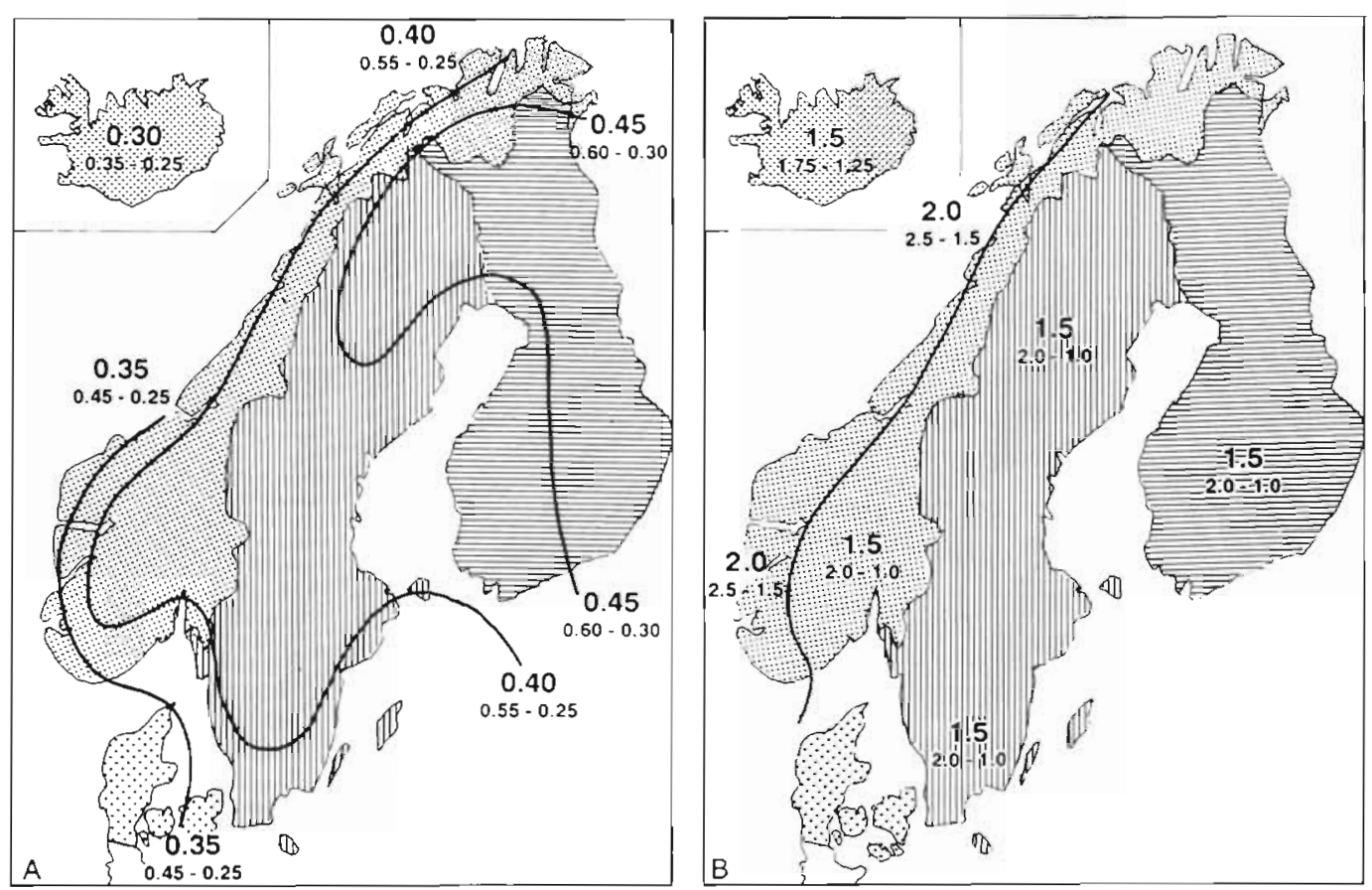

Fig. 2. Climate change scenario for the Nordic countries. (A) Changes in mean surface air temperature (shown are mean annual and winter-summer values) in ${ }^{\circ} \mathrm{C}$ per decade from a 1961 to 1990 baseline. Changes for the Faeroe Islands are the same as for Iceland, and those for Nuuk/Godthåb are the same as for western Norway. (B) Changes in precipitation (shown are accumulated annual and winter-summer values) in percent per decade from a 1961 to 1990 baseline. Changes for the Faeroe Islands are the same as for Iceland, and those for Nuuk/Godthåb are the same as for central Scandinavia

temperature scenario is roughly in agreement with an average of 4 different coupled ocean-atmosphere GCMs in the Nordic region (Fortelius et al. 1994, J. Räisänen 1994), except that the west-east gradient in the summer warming is slightly less in the scenario than in the GCM average.

The precipitation scenario is more problematic than the temperature scenario. The statistically downscaled information is very uncertain - the signal is on the same order of magnitude as the uncertainty. The same uncertainty concerning a regional precipitation response can be found in the comparison between different models in the IPCC (1992) report. The comparison in the IPCC (1992) report is, however, made for equilibrium response simulations only. Manabe et al. (1991) report precipitation results both for a transient and for an equilibrium experiment, but they only give the precipitation change as a zonal average. They find that the transient precipitation response at the time of $\mathrm{CO}_{2}$ doubling is less than the equilibrium response by almost a factor of 2 , but the same overall geographic pattern is found. This difference is consistent with the higher $\mathrm{CO}_{2}$-induced warming in the equilibrium experiment compared with the transient experiment at the time of $\mathrm{CO}_{2}$ doubling. In the latitude range of 50 to $70^{\circ} \mathrm{N}$, Manabe et al. (1991) find that the precipitation rate increase is about $10 \%$ at the time of $\mathrm{CO}_{2}$ doubling (i.e. $70 \mathrm{yr}$ after the start of the experiment). This implies a decadal rate of increase of around $1.5 \%$. Manabe et al. (1992), furthermore, show that the precipitation over continents increases in all seasons of the year in this latitude range. If we assume that the rate of relative precipitation increase is proportional to the rate of warming based on the above-mentioned difference between the equilibrium and transient experiments, we arrive at a ratio of about $4 \%$ per ${ }^{\circ} \mathrm{C}$ of warming. This estimate applies to a zonal mean in a latitude band encompassing the Nordic countries.

The regional and seasonal distribution of the precipitation increase is almost impossible to determine. Nevertheless we will attempt to do this subjectively, but once again we must stress that the range of uncertainty is on the same order of magnitude as the signal we wish to portray. Our strategy is to take the above zonally averaged value from Manabe et al. (1991) as a base rate and to modulate this by seasonal and regional differences in the warming according to the temperature scenario and by the regional precipitation differences indicated by the statistical downscaling described in the previous section. In this subjective endeavor, we must evaluate the likely significance of the regional and seasonal differences in warming implied by the temperature scenario as an indicator of increased precipitation. It appears likely that an over- 
all increase in troposphere temperature will lead to increased precipitation, especially in regions where the relative importance of orographic precipitation is high. This is due to the increased moisture content and moisture transport in the atmosphere which is likely to be associated with the higher temperatures if the relative humidity of the air does not change

The dramatic increase in winter temperatures over the Arctic Ocean and northern continental regions implied by GCM model experiments (typically 4 to $6^{\circ} \mathrm{C}$ at the time of $\mathrm{CO}_{2}$ doubling in transient experiments) leads to extreme precipitation increases if one computes the precipitation increase directly from the winter warming using globally determined ratios of precipitation increase to warming. High precipitation increases derived in this manner are unreasonable because the dramatic increase in surface air temperature over the Arctic Ocean and the northernmost parts of Asia and North America arises due to changes in the frequency and intensity of the strong temperature inversions which occur in these regions during winter. Due to this inversion, the temperature can increase significantly near the surface of the earth without a corresponding increase at higher tropospheric levels (cf. Fig. 8 in Manabe et al. 1991). Local surface warming of this kind is essentially unrelated to moisture transport to a region and to the processes which generate precipitation, and this warming is not associated with a correspondingly large precipitation increase in GCM experiments (cf. Fig. 23 in Manabe et al. 1991).

Based on the above considerations, we computed the increased precipitation in Finland and northernmost Sweden using relatively low values of the ratio of precipitation increase to warming ( 3 to $4 \%$ per ${ }^{\circ} \mathrm{C}$ ). In the North Atlantic and western Norway we used higher values $\left(5\right.$ to $6 \%$ per $\left.{ }^{\circ} \mathrm{C}\right)$ due to the importance of orographic precipitation. This approach is supported by the results of the statistical downscaling given in Table 1 , where the most prominent signal is the relatively large increase found for stations such as Troms $\varnothing$ and Bergen while there is a smaller increase (even a decrease) for the Swedish and Finnish stations. Due to the higher winter warming implied by the temperature scenario, the precipitation increase is larger in winter than in summer, in line with GCM results and the precipitation scenarios which have been derived in the Finnish SILMU project (cf. the section 'Climatic change scenarios', above). Fig. $2 \mathrm{~B}$ shows the precipitation change scenario

\section{SUMMARY AND CONCLUSIONS}

Anthropogenic input of $\mathrm{CO}_{2}$ and other greenhouse gases into the atmosphere will lead to significant changes in the radiation budget of the atmosphere in the coming decades. The effect of these changes on global and especially on regional climate remains somewhat conjectural in spite of recent advances in the computer models used to estimate future climate changes. Coupled ocean-atmosphere GCMs are the most sophisticated tools currently available to assess future climate changes in a consistent manner. These models predict an average global warming rate of approximately $0.3^{\circ} \mathrm{C}$ per decade during the next $100 \mathrm{yr}$ if the current rate of increase in the concentration of greenhouse gases in the atmosphere continues unabated.

The regional distribution of the climate changes is highly uncertain. Available coupled ocean-atmosphere GCM experiments indicate that warming in the North Atlantic area will be slower than on the continents in the same latitude range due to a reduction in the strength of the thermohaline circulation in the North Atlantic. The models do not represent the present-day regional climate of the Nordic region very well. The derivation of climate scenarios based directly on GCM model output in this region is therefore uncertain, but nevertheless we used this information as we considered it to be the best information available.

A statistical downscaling of GCM model results from the MPI was carried out for the Nordic region in order to improve the regional distribution of the climate changes. The statistical method was based on a regression analysis which relates observed monthly mean values of meteorological variabies at ciimatoiogical stations to an EOF decomposition of the monthly mean large-scale atmospheric flow. The regression model was applied to computed circulation changes according to the control and transient runs from MPI in a 30 yr period centered around the middle of the next century. Downscaled temperature changes were broadly in agreement with the grid values from coupled GCMs in this region. Temperature changes in the winter were largest in Finland and northern Scandinavia, but smaller in Iceland and on the Færœe Islands. The changes in the summer season were smaller and more uniform. Precipitation changes varied strongly from station to station and from season to season. On average, the relative increase in the precipitation was positive and on the order of $10 \%$.

The climate change scenario was derived by a subjective evaluation of available coupled ocean-atmosphere GCM experiments together with the results from the statistical downscaling. Relatively great emphasis was put on results from the GCM model from the GFDL because the large-scale sea level pressure distribution in the control run of this model is more realistic than in the other models considered.

The scenario specified a warming rate of $0.3^{\circ} \mathrm{C}$ per decade $\left(0.35^{\circ} \mathrm{C}\right.$ per decade in winter and $0.25^{\circ} \mathrm{C}$ per 
decade in summer) for the western part of the area, increasing to $0.45^{\circ} \mathrm{C}$ per decade $\left(0.6^{\circ} \mathrm{C}\right.$ per decade in winter and $0.3^{\circ} \mathrm{C}$ per decade in summer) in Finland, northern Norway and Sweden. A sinusoidal variation between the summer and winter values was assumed.

The scenario for precipitation changes is more problematic than the temperature scenario. Precipitation changes were assumed to be in the range 3 to $6 \%$ per ${ }^{\circ} \mathrm{C}$ of warming, using the lower part of the range in the continental portion of the area and the higher part of the range along the western coast of Norway, where precipitation is strongly enhanced by orography. The precipitation changes were greater in winter than in summer.

Natural climate variability in the North Atlantic region is of a similar magnitude as the warming computed by coupled ocean-atmosphere GCMs for this region in the next decades. The complex coupling between ocean circulation in the North Atlantic ocean and possible $\mathrm{CO}_{2}$-induced climate warming will make it very difficult to differentiate between anthropogenic and natural climate variability in this region for the next 20 to $30 \mathrm{yr}$.

In view of the large uncertainties involved in the derivation of this scenario, we stress that it must be considered a tentative description of what might happen in the future rather than a prediction of what most likely will happen.

Acknowledgements. This study was carried out as part of the project 'Climate Change and Energy Production', a joint project between Denmark, Finland, Iceland, Norway and Sweden, sponsored by the Nordic Council of Ministers. An expert group was responsible for defining the climate scenario adopted by the project. The members of the expert group are Björn Aune (DNMI, chairman), Bengt Dahlström and Hans Alexandersson (SMHI), Raino Heino (FMI), Trausti Jónsson (IMO) and Tómas Johannesson (NEA). The comments from 3 anonymous reviewers were helpful in improving this paper.

\section{LITERATURE CITED}

Aittoniemi (1992) Influences of climate change in the Finnish energy economy. In: Ostrem $G$ (ed) Nordisk Hydrologisk Konferens 1992 (NHK-92), NH-rapport nr 30. Nordisk Hydrologisk Program, Oslo, p 75-84

Alexandersson H, Dahlström B (1992 Future climate in the Nordic region. Swedish Meteorological and Hydrological Institute, RMK no. 64, Nordköping

Bergthórsson P, Björnsson H. Dýrmundsson Ó, Guðmundsson B, Helgadóttir Á, Jónmundsson JV (1987) The effect of climatic variations on agriculture in Iceland. In: Parry ML, Carter TR, Konijn NT (eds) The impact of climatic variations on agnculture, Vol 1, Assessments in cool temperate and cold regions. Reidel, Dordrecht, p 381-509

Boer GJ, Arpe K, Blackburn M, Déqué M, Gates WL, Hart TL, le Treut H, Roeckner E, Sheinin DA, Simmonds I, Smith RNB, Tokioka T, Wetherald RT, Williamson D (1992) Some results from an intercomparison of the climates simulated by 14 atmospheric general circulation models. J geophys Res 97(D12): 12771-12786

Broecker WS, Peteet DM, Rind D (1985) Does the oceanatmosphere system have more than one stable mode of operation? Nature 315(6014):21-26

Carter TR (1992) The greenhouse effect and Finnish agriculture. Maatilahallinnon aikakauskirja, 1/1992, Helsinki

Carter TR, Holopainen E, Kanninen M (1993) Techniques for developing regional climatic scenarios for Finland. SILMU/Academy of Finland, Rep 2/93, Helsinki

Carter TR, Parry ML, Nishioka S, Harasawa H (1992) Preliminary guidelines for assessing impacts of climate change. IPCC, WMO, UNEP, Environmental Change Unit, Oxford

Chapman WL, Walsh JE (1993\} Recent variations of sea ice and air temperature in high latitudes. Bull Am Meteorol Soc $74(1): 33-47$

Cubasch U, Hasselmann K, Höck H, Maier-Reimer E, Mikolajewicz U, Santer BD, Sausen R (1991) Time-dependent greenhouse warming computations with a coupled oceanatmosphere model. Max-Planck-Institut für Meteorologie, Rep no. 67, Hamburg

Cubasch U, Hasselmann $K_{1}$ Höck $H_{1}$ Maier-Reimer $E_{1}$ Mikolajewicz U, Santer BD, Sausen R (1992a) Time-dependent greenhouse warming computations with a coupled oceanatmosphere model. Clim Dyn 8:55-69

Cubasch U, Hegerl G, Hellbach A, Höck H, Mikolajewicz U, Santer BD, Voss R (1994) A climate change simulation starting at an early time of industrialization. Max-PlanckInstitut für Meteorologie, Rep no. 124, Hamburg

Cubasch U, Santer BD, Hellbach A, Hegerl G, Höck H, MaierReimer E, Mikolajewicz U, Stössel A, Voss R (1992b) Monte Carlo climate change forecasts with a coupled ocean-atmosphere model. Max-Planck-Institut für Meteorologie, Rep no. 97, Hamburg

Delworth T, Manabe S, Stouffer RJ (1993) Interdecadal variations of the thermohaline circulation in a coupled oceanatmosphere model. J Clim 6:1993-2011

Eliasen E, Laursen L (1990) On the effects of horizontal resolution and diffusion in a two-layer general circulation model with a zonally symmetric forcing. Tellus 42:520-530

Ellingson RG, Ellis J, Fels S (1991) The intercomparison of radiation codes used in climate models: long wave results. J geophys Res 96:8929-8953

Fenger J, Torp U (eds) (1992) Drivhuseffekt og klimaændringer hvad kan det betyde for Danmark. Miljøministeriet, København

Fortelius C, Holopainen E, Kaurola J, Ruosteenoja K, Räisänen $J$ (1994) Climate models and scenarios. In: Kanninen M. Heikinheimo P (eds) The Finnish research programme on climate change, second progress report. SILMU/Academy of Finland, Rep 1/93, Helsinki, p 45-51

Giorgi F, Marinucci MR, Visconti G (1992) A $2 \times \mathrm{CO}_{2}$ climate change scenario over Europe generated using a limited area model nested in a general circulation model. 2. Climate change scenario. J geophys Res 97(D9): 1001.1-10028

Greco S, Moss RH, Viner D, Jenne R (1994) Climate scenarios and socioeconomic projections for IPCC WG II assessment. Intergovernmental Panel on Climate Change Working Group II, WMO, UNEP, Washington, DC

Hansen J, Fung I, Lacis A, Rind D, Lebedeff S, Ruedy R, Russel $G$, Stone P (1988) Global clmate changes as forecast by Goddard Institute for Space Studies three-dimensional model. J geophys Res 93(D8):9341-9364

Hasselmann K. Sausen R, Maier-Reimer E, Voss R (1993) On the cold start problem with coupled ocean-atmosphere models. Clim Dyn 9:53-61

Hewitson BC, Crane RG (1992) Regional-scale climate pre- 
diction from the GISS GCM. Palaeogeogr Palaeoclimatol Palaeoecol 97:249 -267

IPCC (Intergovernmental Panel on Climate Change) (1990) Climate change: the IPCC scientific assessment. Cambridge University Press, Cambridge

IPCC (Intergovernmental Panel on Clmate Change) (1992) Climate change 1992: the supplementary report to the IPCC scientific assessment. Cambridge University Press, Cambridge

Kaas E (1993a) Greenhouse induced climate change in the Nordic countries as simulated with the Hamburg climate model. Part 1: direct model output. Danish Meteorological Institute, Scientific Rep no. 93-2, Copenhagen

Kaas $E$ (1993b) Greenhouse induced climate change in the Nordic countries as simulated with the Hamburg climate model. Part 2: statistical interpretation. Danish Meteorological Institute, Scientific Rep no. 93-3, Copenhagen

Kaas E (1993c) Ultra low-frequency large-scale flow patterns and local blocking of the westerlies in the northern hemisphere. PhD thesis, Danish Meteorological Institute. Scientific Rep no. 93-6, Copenhagen

Kaas $\mathrm{E}$ (1994) An update of statistically interpreted greenhouse induced climate change in the Nordic countries. Informal report, Danish Meteorological Institute, Copenhagen

Källén E, Huang XY (1987) A simple model for large-scale thermohaline convection. Dyn Atmos Ocean 11:153-173

Karl TR, Wang WC, Schlesinger ME, Knight RW, Portman D (1990) A method of relating general circulation model simulated climate to the observed local climate. Part I: seasonal statistics. J Clim 3:1053-1079

Karlén W, Friis-Christensen E, Dahlström B (1993) The earth's climate. Elforsk A.B, Stockholm

Kettunen L, Mukula J, Pohjonen V, Rantanen O, Varjo U (1987) The effect of climatic variations on agriculture in Finland. In: Parry ML, Carter TR, Konijn NT (eds) The impact of climatic variations on agriculture, Vol 1, Assessments in cool temperate and cold regions. Reidel, Dordrecht, p 511-614

Lamb PJ, Peppler RA (1987) North Atlantic Oscillation: concept and an application. Bull Am Meteorol Soc 68(10): $1218-1225$

Lindzen RS (1991) Some coolness concerning global warming. Bull Am Meteorol Soc 71:288-299

Lunkeit F, Sausen R, Oberhuber JM (1994) Climate simulations with the global coupled atmosphere-ocean model ECHAM2/OPYC. Part I: Present-day climate and ENSO events. Max-Planck-Institut für Meteorologie, Rep no. 132, Hamburg

Manabe S, Spelman MJ, Stouffer RJ (1992) Transient responses of a coupled ocean-atmosphere model to gradual changes of atmospheric $\mathrm{CO}_{2}$. Part II: seasonal response. J Clim 5:105-126

Manabe S, Stouffer RJ (1988) Two stable equilibria of a coupled ocean-atmosphere model. J Clim 1:841-866

Manabe S, Stouffer RJ, Spelman MJ, Bryan K (1991) Transient responses of a coupled ocean-atmosphere model to gradual changes of atmospheric $\mathrm{CO}_{2}$. Part I: annual mean response. J Clim 4:785-818

Marinucci MR, Giorgi F (1992) A $2 \times \mathrm{CO}_{2}$ climate change scenario over Europe generated using a limited area model nested in a general circulation model. 1. Present-day seasonal climate simulation. J geophys Res 97(D9): 9989-10009

Meehl GA, Washington WM, Karl TR (1993) Low-frequency variability and $\mathrm{CO}_{2}$ transient climate change. Clim Change 8:117-133

Miljoverndepartementet (1991) Drivhuseffekten, virkninger og tiltak. Miljoverndepartementet, Oslo

Mitchell JFB, Senior CA, Ingram WJ (1989) $\mathrm{CO}_{2}$ and climate a missing feedback? Nature 341 (6238):132-134

Murphy JM (1992) A prediction of the transient response of clunate. Hadley Centre, Climate Research Technical Note no. 32, Bracknel]

Murphy JM (1995) Transient response of the Hadley Centre coupled ocean-atmosphere model to increased carbon dioxide. Part I: control climate and flux adjustment. J Clim 8(1):36-56

Murphy JM, Mitchell JFB (1995) Transient response of the Hadley Centre coupled ocean-atmosphere model to increased carbon dioxide Part II: spatial and temporal structure of response. J Clim 8(1):57-80

Randall DA, and 30 other authors (1992) Intercomparison and interpretation of surface energy fluxes in atmospheric general circulation models. J geophys Res 97(D4): 3711-3724

Räisänen J (1994) A comparison of the results of seven GCM experiments in northern Europe. Geophysica 30(1-2):3-30

Räisänen P (1994) Single column experiments with the ECMWf, DWD and Arpege radiation schemes. Rep DM69. Department of Meteorology, Stockholm University, Stockholm

Roeckner E, Arpe K, Bengtson L, Brinkop S, Dümenil L, Esch M. Kirk E, Lunkeit F, Ponater M, Rockel B, Sausen R, Schlese U, Schubert S, Windelband M (1992) Simulation of the present-day climate with the ECHAM model: impact of model physics and resolution. Max-Planck-Institut für Meteorologie, Rep no. 93, Hamburg

Sælthun NR (1992) Klimaendringer og energiproduksjon en orientering. Vannet i Norden (Newsletter of the Nordic Association for Hydrology) 25(2):8-12

Sælthun NR, Einarsson $\mathrm{K}$, Lindström $G$, Thomsen $T$, Vehvlärnen B (1994a) Simulation of climate change impacts on runoff in the Nordic countries. Part A. Model and catchments. In: Kern-Hansen C, Kosbjerg D, I homsen R (eds) Nordic Hydrological Conference 1994 (NHK-94), NHP rapport nr 34. Nordic Hydrological Program, Copenhagen, p 3-12

Sælthun NR, Bergström S, Einarsson K, Thomsen T, Vehviläinen B (1994b) Simulation of climate change impacts on runoff in the Nordic countries. Part B. Climate and runoff scenarios. In: Kern-Hansen C, Rosbjerg D, Thomsen R (eds) Nordic Hydrological Conference 1994 (NHK-94), NHP-rapport nr 34. Nordic Hydrological Program, Copenhagen, p 13-25

Sausen R, Barthel K, Hasselmann K (1988) Coupled oceanatmosphere models with flux correction. Clim Dyn 2:145-163

Stouffer RJ, Manabe S, Bryan K (1989) Interhemispheric asymmetry in climate response to a gradual increase of $\mathrm{CO}_{2}$. Nature 342(6250):660-662

Takano Y, Liou KN, Minnis P (1992) The effects of small ice crystals on cirrus infrared radiative properties. J Atmos Sci 49:1487-1493

von Storch H, Zorita E, Cubasch U (1993) Downscaling of global climate change estimates to regional scales: an application to Iberian rainfall in wintertime. J Clim 6:1161-1171

Walsh JE, Crane RG (1992) A comparison of GCM simulations of Arctic climate. Geophys Res Lett 19(1):29-32

Washington WM, Meehl CA (1989) Climate sensitivity due to increased $\mathrm{CO}_{2}$ : experiments with a coupled atmosphere and ocean general circulation model. Clim Dyn 4:1-38

Weisse R, Mikolajewicz U, Maier-Reimer E (1993) Decadal variability of the North Atlantic in an ocean general circulation model. Max-Planck-Institut für Meteorologie, Rep no. 108 , Hamburg 